Jon Bodnar, Alison Valk, and Brian Mathews

\title{
Challenging your students Using a contest to promote the library
}

M any academic libraries now offer more than just a quiet place to study and access information. They offer students a suite of computing, programming, and design resources. However, because students rarely associate these tools with the traditional academic library, many of them remain unaware of what the library has to offer. As more libraries provide support for student collaboration, computing, and creativity, they must nd new ways to tell students about their resources and to create opportunities for students to use them.

Contests are an effective way for libraries to increase student awareness. A successful contest provides students with an interactive, competitive experience through which they can discover or possibly rediscover the importance of their campus library.

\section{Designing a multimedia contest}

In the fall semester of 2007, the Georgia Tech Library launched its multimedia contest Flash in the Pan. This contest invited participants to create a short animated clip on a theme of their choosing using Adobe Flash and related programs. ${ }^{1}$

Flash in the Pan offered students an opportunity to explore the library s multimedia studio resources. Those resources included an array of software programs, training workshops, and personalized assistance, as well as the librarys collection of print and electronic technical books and self-paced DVD tutorials.

Flash in the Pan also allowed Georgia Tech students to increase their understanding of the importance of the library to their academic and creative achievements. By highlighting the multimedia resources, the contest increased student awareness of the library $s$ wide range of services and applications and enabled them to see the library as a multifaceted learning environment. Ultimately, Flash in the Pan inspired students to learn new technologies and allowed the library to secure its place on campus as a meeting ground for the exploration of new ideas.

\section{Key points for launching a contest}

Developing, implementing, and running a successful library contest is dif cult. The best advice is to take your time and to plan carefully. If you are considering running a contest, here are a few important points to consider.

Establish clear goals and expectations. Every long-term project bene ts from having clear goals and expectations. Designing and implementing a contest is no different. De ne your goals and expectations at the beginning of your project, and keep an easily accessible record of them along with a project timeline, task list, and list of important milestones. Having ready access to this information will ensure that everyone knows what needs to be done and who is responsible.

Ask people outside of your department for advice. Librarians and library staff know who is responsible for providing speci c services,

Jon Bodnar is reference and subject librarian, e-mail: jon. bodnar@library.gatech.edu, Alison Valk is information associate, e-mail: alison.valk@library.gatech.edu, and Brian Mathews is reference and subject librarian, email: brian.mathews@library.gatech.edu, at Georgia Tech Library.

c 2008 Jon Bodnar, Alison Valk, and Brian Mathews 
but students do not know about the behindthe-scenes division of labor. They see the library as one building offering a number of services. Use this as a opportunity to talk to people outside of your department about your contest. Ask them for advice and for suggestions for improvement. Their input will offer you a new perspective on your contest, help you to align your contest with the overarching goals of the library, and help you to make your contest more understandable and inviting to the students.

Network and promote. A successful contest creates opportunities for you to connect with students. Actively seek new opportunities to communicate with small groups of students who may be interested in the contest and in the library resources associated with it. Also, remember that communicating with these students is not a one-time deal. Reach out to them in a variety of ways and at different times during the life of the contest.

There are many ways to communicate with students. Here are a few things to explore:

Student newspaper

Posters (inside and outside of the library)

Departmental mailing lists (both faculty lists and student lists)

Faculty contacts (especially in departments whose students are heavy users of the library resources related to the contest)

Library homepage

Blogs

Word-of-mouth campaigns

Flyers/handouts

Facebook

Student computer labs (inside and outside of the library)

Web site created for your contest

Creatively engage students. One goal of a library contest is to engage the students creatively, so feel free to design a contest that requires that they devote some time and energy to ful lling its entry requirements. If they are successful in achieving the creative goals that they set for themselves while participating in your contest, they will associate that success with the library. They will also better understand the bene $t$ that the library is to them.

Engaging students through a library contest is a matter of nding the right balance between two concerns. First, you must ask students to do something that is in line with the educational mission of your college or university and the type of work that students often do on your campus. This will ensure that students have the skills that are necessary to participate in your contest. Second, you must also ask students to do something that is suf ciently different from the work that they do in their classes on a daily basis so that they will not view participation in your contest as just another class project or just more work to do.

Make the contest attractive to students. The more attractive your contest is to students, the more likely they will be to enter it. Here are two suggestions to help you increase the attractiveness of your contest to students.

- Use high-pro le people as judges or spokespersons for your contest. Find out who students respect and aspire to be like, and ask them if they are willing to participate in your contest or if they are willing to make an appearance in support of it. This will increase student interest and raise their competitive spirits.

- Offer a great prize. Students will not enter your contest if they do not think that its grand prize is worth the effort it takes to win it, so take the time to discover what students really want, and nd a way to offer it as a prize for your contest. Additionally, if your contest targets students with speci c abilities, make sure that your prize is attractive to students who have that particular skill set.

\section{Conclusion}

Library contests are relatively commonplace. However, some contests are more successful than others. Awarding a prize to students simply for writing a good paper limits your potential to introduce them to the wide range of resources that your library provides. Be

(continues on page 229) 
to the meeting with Leshner, as discussed above. Finally, a week or two after the Leshner meeting, ICOLC concluded its deliberations with the endorsement of the resolution by 62-library consortia. These cascading events, nicely interspersed by two-to-four weeks, were critical in building advocacy and visibility, but the timing was unplanned and just plain lucky.

\section{Courageous leadership}

I want to offer sincere and genuine recognition of the courageous leadership shown by Alan Leshner in this process. It is to Leshner s great credit that he was willing to reconsider a decision that he had supported and endorsed. As an administrator and leader, it is easy to become personally invested in decisions. However, upon hearing the voices and concerns of the library community (and, I believe, some of his membership representatives) it is a measure of Leshner s leadership and administrative courage that he did not react stubbornly and defensively. Rather, he reconsidered, initiated a reopening of discussions with JSTOR, and after renegotiations, reversed the original

("MLibrary2.0," continued from page 206)

think more openly and broadly about how users and staff work and encouraged thinking on a large scale about delivery of content and services. It has prompted us as a community to try new things and to see new possibilities. What s next? We don t know. We have only begun to create, share, and network! ${ }^{6}$

\section{Notes}

1. MLibrary 2.0 promotional Web site, www.lib.umich.edu/lib20/.

2. Flickr and Facebook groups to encourage sharing and networking, ickr.com decision. He deserves recognition as well as our admiration and thanks.

\section{Conclusion}

On the basis my experience, the successful advocacy effort with AAAS depended on commonality of values, personal commitment to the issue, reaching the AAAS membership, luck, and leadership. These factors led to the reversal of the decision to cease contributing new content from its premier journal, Science, to the JSTOR platform. Clearly, some of these characteristics are unique to the AAAS/JSTOR issue. It is interesting to think which factors could be applied and which factors would be new in a similar effort with a different nonpro t organization, such as the American Psychological Association, or even a for-pro $t$ publisher. The lessons of this initiative are useful and worth the careful consideration of the library community.

But in conclusion the nal word must be this: after years of outrageous pricing schemes, intractable usage policies, in exible licensing schemes, and Machiavellian mergers and consolidations, it was good to win one. $\boldsymbol{n}$

/groups/mlibrary2_0/ and umichigan. facebook.com/group.php?gid=2825620230.

3. Aggregated RSS feed, www.lib.umich. edu/lib20/uberfeed.html.

4. Pre-Shelf Life of Library Materials, www.flickr.com/photos/alexis_medea /sets/72157601347637401/.

5. Google Maps/Flickr mashup, www.lib. umich.edu/labs/maps/index.html.

6. Thanks to the task force members: Laurie Alexander (co-chair), Dave Carter (co-chair), Suzanne Chapman, Robyn Cleveland, Bill Dueber, Jake Glenn, Kat Hagedorn, Donna Hayward, Susan Hollar, Scott Martin, and Julie Weatherbee. $\pi$

\section{Note}

1. Visit weblog.library.gatech.edu/news /2007/12/11/ ash-in-the-pan-winner/ to see Georgia Tech Library s Flash in the Pan 2007 winner. $\boldsymbol{n}$ 